(c) American Dairy Science Association, 2005.

\title{
Time of Feed Delivery Affects the Feeding and Lying Patterns of Dairy Cows
}

\author{
T. J. DeVries and M. A. G. von Keyserlingk \\ Animal Welfare Program, Faculty of Agricultural Sciences, \\ The University of British Columbia, Vancouver, BC, V6T 1 Z4 Canada
}

\begin{abstract}
The objective of this experiment was to determine whether it is the return from milking or delivery of fresh feed that has the greater effect on the daily patterns of feeding and lying behavior of dairy cattle. Forty-eight lactating Holstein cows were subjected to each of 2 treatments in a $2 \times 2$ cross-over design replicated over time. The treatments were 1) milking and feed delivery times coinciding and 2) feed delivery $6 \mathrm{~h}$ after milking. Cows were milked twice daily at 0500 and $1700 \mathrm{~h}$. An electronic monitoring system was used to measure the time spent at the feed alley. Time-lapse video was used to quantify the lying time and incidence of aggressive displacements of the cows at the feed alley. Cows increased their total daily feeding time by $12.5 \%$ when fed $6 \mathrm{~h}$ after milking. This change was driven by an $82 \%$ increase in feeding time during the first hour immediately following the delivery of fresh feed and a $26 \%$ decrease in feeding time during the first hour after milking. The delivery of feed $6 \mathrm{~h}$ after milking did not change the daily lying time of the cows, but did decrease the latency to lie down after milking by $20 \mathrm{~min}$. The reduction in feeding time after milking and decreased latency to lie down resulted in a tendency for less aggressive interactions at the feed alley after the cows returned from milking. These results indicate that the delivery of fresh feed has a greater impact on stimulating feeding behavior than does the return from milking and that changes in feeding management can affect both the feeding and lying behavior of dairy cows.
\end{abstract}

(Key words: feed delivery, feeding behavior, dairy cow)

\section{INTRODUCTION}

Grazing cattle typically display a diurnal feeding pattern, consuming the majority of their daily intake during the daytime (Hafez and Bouissou, 1975). Intensively housed dairy cattle have been reported to exhibit simi-

Received August 17, 2004.

Accepted October 12, 2004.

Corresponding author: T. DeVries; e-mail: trevorjd@interchange. ubc.ca. lar patterns. Haley et al. (2000) showed that individually housed cows in tie stalls tended to eat the majority of their food during the day, with peak feeding activity occurring immediately following milking and feeding. Similar responses to milking and feeding have also been demonstrated for cows in free-stall housing (Tanida et al., 1984; DeVries et al., 2003a; Wagner-Storch and Palmer, 2003).

On many commercial dairy farms, fresh feed is delivered to the pen while cows are away for milking. The presence of fresh feed when cows return from milking is thought to stimulate cows to feed rather than to lie down, thereby potentially reducing the risk of mastitis by providing more time for the teat canals to close before they contact the stall surface (Tyler et al., 1997; Johansson et al., 1999). Unfortunately, little is known about what factors actually stimulate cows to move to the feed alley. Moreover, there is also limited work on the effect of providing fresh feed upon return from milking on latency to lie down after milking. Thus, the objective of this experiment was to evaluate the effect of when fresh feed is delivered relative to milking on the feeding and lying behavior of lactating dairy cows.

\section{MATERIALS AND METHODS}

\section{Animals, Housing, and Diet}

Nineteen primiparous and 29 multiparous (parity = $2.9 \pm 0.8$; mean $\pm \mathrm{SD}$ ) lactating Holstein dairy cows were used in the study. The animals were $108.5 \pm 17.9$ DIM at the beginning of the data collection period. The cows were housed in a free-stall barn located at The University of British Columbia Dairy Education and Research Center (Agassiz, BC, Canada) and were managed according to the guidelines set by the Canadian Council on Animal Care (1993). The cows were fed ad libitum a TMR consisting of $17 \%$ corn silage, $17 \%$ grass silage, $7 \%$ alfalfa hay, 9\% fourth-cut grass hay, $15 \%$ energy blend, and $35 \%$ concentrate mash on a DM basis. The composition of the TMR was $51 \% \mathrm{DM}$ and contained (DM basis) $18 \% \mathrm{CP}, 32 \% \mathrm{NDF}, 19 \% \mathrm{ADF}, 1.0 \% \mathrm{Ca}$, and $0.5 \% \mathrm{P}$. The TMR was formulated according to the NRC (2001) nutrient requirement recommendations for 
high-producing dairy cows. Cows consumed their feed from a feed alley with access via a pendulous feed-rail and had $0.55 \mathrm{~m}$ of feeding space per animal. In addition, each cow had access to a free stall that was deep bedded with sand. The animals were milked between 0500 and $0530 \mathrm{~h}$ in the morning and between 1700 and $1730 \mathrm{~h}$ in the afternoon. The animals were milked in a double12 parallel milking parlor and were moved to and from the parlor together in their respective groups. Milk yields were automatically recorded at each milking.

Samples of the TMR were taken at each feeding and from the orts each day of the experiment. Dry matter of the samples was determined by drying in a hot-air oven at $60^{\circ} \mathrm{C}$ for $3 \mathrm{~d}$. The DMI for each group for each day on treatment were recorded by subtracting the DM weight of the orts from the DM weight of the fresh feed. The daily orts averaged $7.5 \pm 4.4 \%$ (mean \pm SD) of the fresh feed provided over the course of the experiment.

\section{Experimental Treatments and Design}

The 48 lactating cows were used in a $2 \times 2$ cross-over design replicated over time. The animals were divided into 4 equal groups of 12 cows, which were balanced according to projected 305-d milk production $(10,610.4$ $\pm 1859.9 \mathrm{~kg}$; mean $\pm \mathrm{SD}$ ), average DIM (108.5 \pm 17.9$)$, and average parity $(2.2 \pm 1.1)$. Each group was subjected to each of 2 treatments. The treatments were 1 ) milking and feed delivery times coinciding and 2) delivery of feed $6 \mathrm{~h}$ after milking. Orts were removed immediately prior to the delivery of fresh feed for each day for both treatments, at $0515 \mathrm{~h}$ and $1115 \mathrm{~h}$, respectively. Feed push-up occurred twice daily: $6 \mathrm{~h}$ after feeding for each group. Feeding and pushing up feed at 6 -h intervals ensured that feed was available to the cows for all hours in the day in which they were in their respective pen.

All groups were housed together for 1 wk prior to the experimental phase to allow for social adaptation. Initially, the 2 treatments were applied to the first 2 groups of cows for a 3-d adjustment period followed by $7 \mathrm{~d}$ of data collection. After this was completed, the treatments were switched between the groups. Again, animals were given a 3 -d adjustment period followed by $7 \mathrm{~d}$ of observations on the new treatment. This same procedure was then repeated with the 2 remaining groups of cows.

\section{Behavioral Recording}

The lying and feeding behavior and number of aggressive interactions for all cows were recorded for $7 \mathrm{~d}$ per treatment. Lying and aggressive behavior were monitored using time-lapse video equipment. The animals were videotaped using 2 video cameras (Panasonic WV-
BP330; Osaka, Japan) per pen, a time-lapse videocassette recorder (Panasonic AG-6540), and a video multiplexer (Panasonic WJ-FS 216). For each pen, a video camera was located $6 \mathrm{~m}$ above the feed alley and another camera was located $10 \mathrm{~m}$ above the free stalls. Red lights $(100 \mathrm{~W})$, hung adjacent to the cameras, were used to facilitate recording at night. Individual animals were identified with unique alphanumeric symbols made with hair dye (Clairol's Nice and Easy \# 122, Natural Black, or Clairol's L'image Maxiblonde, depending on hair color; Stamford, CT) on the back. Feeding behavior was monitored for the entire experiment using an electronic feed alley monitoring system (GrowSafe Systems Ltd.; Airdrie, AB, Canada) that recorded individual cow presence (hits: a reading that occurs every $6 \mathrm{~s}$ for the duration of time the cow is feeding) at the feed alley. This system has previously been described (DeVries et al., 2003b) and validated (DeVries et al., 2003c).

Measuring feeding behavior. The feeding behavior of individual cows was quantified using measures of feeding time, as this has previously been described as the most repeatable and sensitive measure of feeding behavior (DeVries et al., 2003b). Because the scanning interval of the electronic monitoring system was $6 \mathrm{~s}$, we were able to convert the number of hits into feeding time (i.e., number of hits $\times 6 \mathrm{~s} / 60 \mathrm{~s}$ per $\min =\min$ feeding time). Total daily feeding time was calculated for each cow for each treatment day. Feeding time was also calculated for the 60-min period following the return of the last cow from milking (appearance of the last cow to enter the pen after milking marked the beginning of this period) and following the provision of fresh feed (when delivered at 1130 and $2330 \mathrm{~h}$ ). These 60-min periods were identified in this study and in a previous study (DeVries et al., 2003a) as the times when the largest concentrations of cows are present at the feed alley.

Measuring lying behavior. Daily lying times were obtained from the video recordings, using instantaneous scan sampling once every $10 \mathrm{~min}$ (Fregonesi et al., 2004). In addition, we monitored the length of time it took cows to lie down upon return from the milking parlor (i.e., latency to lie down). This was quantified by continuously watching the video recordings from the time the cows returned from the parlor until they lay down in one of the stalls.

Measuring aggressive behavior. Aggressive displacements at the feed alley were recorded during the 60-min period following the return from milking and following the provision of fresh feed (when delivered at 1130 and $2330 \mathrm{~h}$ ). A displacement was noted when a butt or a push from the actor (instigator) resulted in the 
Table 1. Total daily feeding time and for the 60-min period following the return from milking for both treatments and for the 60-min period following the delivery of fresh feed for when cows were fed $6 \mathrm{~h}$ postmilking. ${ }^{1}$ The least squares SE and $P$ values for the test of treatment are provided.

\begin{tabular}{lllll}
\hline & \multicolumn{2}{c}{ Treatment } & & \\
\cline { 2 - 5 } & $\begin{array}{l}\text { Feed delivery } \\
\text { and milking } \\
\text { time coincide }\end{array}$ & $\begin{array}{l}\text { Feed delivery } \\
6 \mathrm{~h} \text { after } \\
\text { milking }\end{array}$ & SE & $P$ \\
\hline Daily $(\mathrm{min} / \mathrm{d})^{2}$ & 191.9 & 215.9 & 3.41 & 0.016 \\
${\text { Return from milking }(\mathrm{min})^{3}}_{\text {Delivery of fresh feed }(\mathrm{min})^{4}}$ & 15.6 & 11.6 & 0.39 & 0.006 \\
\hline
\end{tabular}

\footnotetext{
${ }^{1}$ Data were averaged for $7 \mathrm{~d}$ per treatment for 4 groups of cows (12 cows per group).

${ }^{2}$ Average feeding time per cow per day.

${ }^{3}$ Average feeding time per cow during the 60 min following the return from the milking parlor.

${ }^{4}$ Average feeding time per cow during the 60 min following provision of fresh feed.
}

complete withdrawal of the reactor's head from beneath the feed rail (DeVries et al., 2004).

\section{Data Analysis}

For the analysis of feeding behavior, DMI, milk yield, lying behavior, and displacements from the feed alley, the pen was considered as the experimental unit, with measures from multiple days and cows averaged to create one observation per pen per treatment. Treatment effects on the feeding behavior measures, DMI, milk yield, lying behavior measures, and number of displacements were tested by one-sample paired $t$-tests with 3 degrees of freedom.

Overall, treatment response was tested using pen as the experimental unit. However, to determine whether cows with higher feeding times were more affected by treatment, we used a within-cow test. Feeding times ( 60 min after milking and feeding) during the 2 treatments were compared using the regression procedure of SAS (1985). A test of the intercept term (difference from zero) revealed the mean effect of treatment, and a test of the slope (difference from one) assessed if the response to treatment varied in relation to the initial value.

\section{RESULTS}

\section{Feeding Behavior, Feed Intake, and Milk Yield}

When animals were fed $6 \mathrm{~h}$ after milking, they increased their total daily feeding time by $12.5 \%$ (Table 1). This change was predominantly driven by an $82 \%$ increase in feeding time during the $60 \mathrm{~min}$ following the delivery of fresh feed and a $26 \%$ decrease in feeding time during the 60 min after milking. Figure 1 illustrates the presence of fewer animals feeding during the period immediately following the return from milking when no fresh feed was delivered. Further, we noted a substantial increase in the number of animals feeding after the delivery of fresh feed at 1130 and $2330 \mathrm{~h}$ compared with when they were fed at milking time.

Because there were significant changes in feeding time when cows were fed $6 \mathrm{~h}$ after milking, we used linear regression to determine how the individual cows responded to the treatment after they returned from milking (Figure 2a) and after they received fresh feed (Figure $2 b$ ). The coefficient of determination was statistically significant $(P<0.001)$ for both relationships, indicating that cows were relatively consistent in feeding times across treatments. For feeding time after milking, the intercept $(2.40 \pm 1.55$; mean $\pm \mathrm{SE})$ was not significantly greater than zero $(P=0.13)$, but the slope was $<1(0.58 \pm 0.09 ; P<0.001)$. For the feeding time after delivery of fresh feed, the intercept was greater than zero $(12.53 \pm 2.61 ; P<0.001)$, and the slope was not different than $1(1.00 \pm 0.15 ; P=0.99)$.

There was no difference in DMI when groups had fresh feed upon return from milking compared with when they were fed $6 \mathrm{~h}$ after milking $(22.9 \pm 0.4 \mathrm{vs}$. $22.2 \pm 0.4 \mathrm{~kg} / \mathrm{d}$ per cow; $P=0.3$ ). Additionally, there was no difference in milk yield when groups had fresh feed upon return from milking compared with when they were fed $6 \mathrm{~h}$ after milking $(38.1 \pm 0.6$ vs. $37.1 \pm$ $0.6 \mathrm{~kg} / \mathrm{d}$ per cow; $P=0.3$ ).

\section{Lying Behavior}

Cows spent on average $12.3 \mathrm{~h} / \mathrm{d}$ lying down, regardless of treatment ( $\mathrm{SE}=0.32 ; P=0.9$ ). However, the distribution of lying time throughout the day was affected by the timing of fresh feed delivery. Those cows that were fed $6 \mathrm{~h}$ after milking showed 4 peaks of lying activity compared with the 2 extended periods of lying activity observed for the cows provided fresh feed upon return from milking (Figure 3). Moreover, cows that did not have fresh feed upon return from milking showed an 


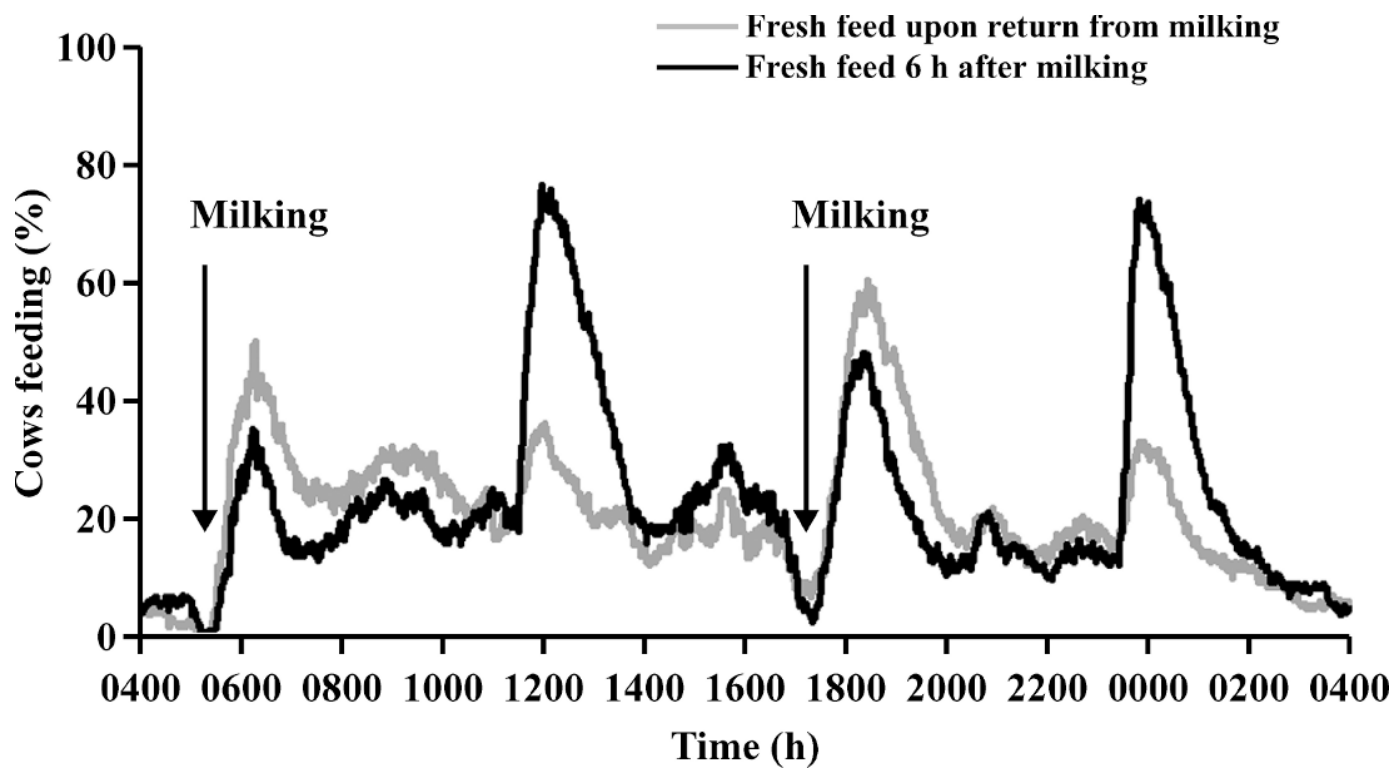

Figure 1. Percentage of cows per group present at the feed alley over a 24 -h period (percentage for each 60 -s interval during the day) for 2 treatments: 1) cows were milked and fed at 0530 and $1730 \mathrm{~h}$ and 2) cows were milked at 0530 and $1730 \mathrm{~h}$ and fed at 1130 and 2130 h. Data were averaged for $7 \mathrm{~d}$ per treatment of 4 groups, each containing 12 cows. Data are presented from $0400 \mathrm{~h}$, as this was a time of low feeding activity for both treatments.

average latency to lie down of $45.1 \mathrm{~min}$ vs. $65.7 \mathrm{~min}$ for cows with access to fresh feed upon the return from milking $(\mathrm{SE}=0.83 ; P<0.001)$.

\section{Aggressive Behavior at the Feed Alley}

During the 60 min after milking, cows physically displaced one another from the feed alley at a frequency of 1.03 displacements per cow when provided access to fresh feed and 0.67 displacements per cow when fresh feed was provided later $(\mathrm{SE}=0.11 ; P=0.1$ ). During the 60-min observational period after the delivery of fresh feed, we observed no significant difference in the frequency of displacements at the feed alley when cows were fed at the time of milking compared with when they were fed $6 \mathrm{~h}$ after milking (1.03 vs. 1.11 displacements per cow; $\mathrm{SE}=0.11 ; P=0.5$ ).

\section{DISCUSSION}

Cows spent $26 \%$ more time feeding during the hour after the return from milking when provided access to fresh feed compared with when they did not have fresh feed upon the return from milking. However, providing fresh feed $6 \mathrm{~h}$ after milking increased feeding time by $82 \%$ during the hour after feed was delivered, such that daily feeding time was $12.5 \%$ greater when cows were fed in this way. To our knowledge, this is the first published evidence that separating times of milking and delivery of fresh feed affects the pattern of feeding and increases total daily feeding time.

There was substantial variation among cows in their response to treatment. Cows that had the highest feeding time postmilking when fed at the time of milking had the greatest decreases in feeding time postmilking when feed was delivered $6 \mathrm{~h}$ after milking. Alternatively, all cows showed a similar increase in feeding time during the first hour after feeding when fed $6 \mathrm{~h}$ postmilking. This substantial increase in feeding time by all cows during the first hour after the 6-h delayed delivery of fresh feed indicates that the delivery of fresh feed is a much stronger stimulus to get cows to feed than the return from the milking parlor.

It is also interesting to note that when the cows were fed $6 \mathrm{~h}$ after milking, they shifted their daily feeding pattern. Previously, dairy cows have been described as crepuscular feeders, being influenced by the timing of sunrise and sunset (Albright, 1993). However, the results of this study indicate that the daily feeding pattern of dairy cows kept indoors is more affected by the timing of fresh feed delivery than by the time of day.

Group feed intakes were used to calculate the average DMI per cow per treatment, and we found no effect of treatment on this measure. We also found no effect of treatment on the milk yield of the cows. However, this study was designed to test predictions concerning feeding behavior and does not provide a strong test of intake or milk yield differences. The regression analysis on 


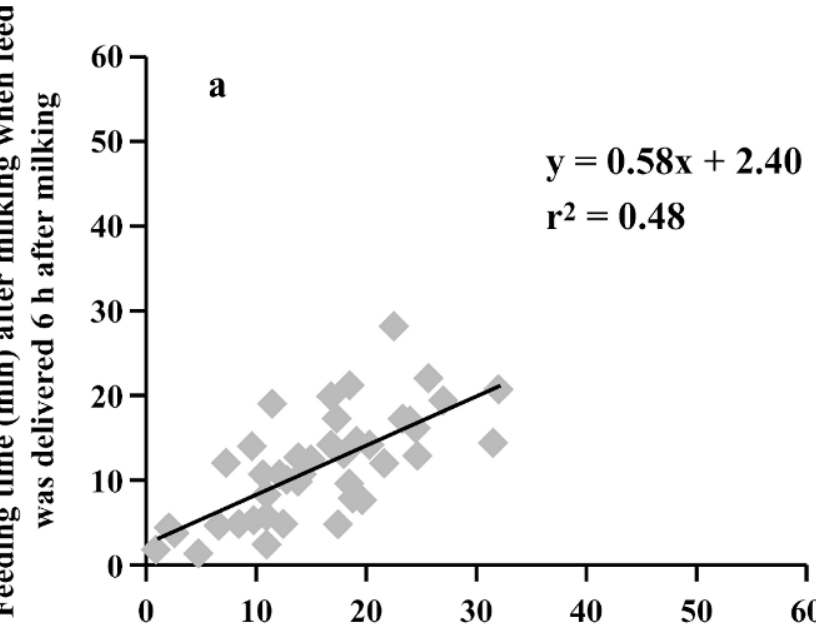

Feeding time (min) after milking when feed was delivered at time of milking

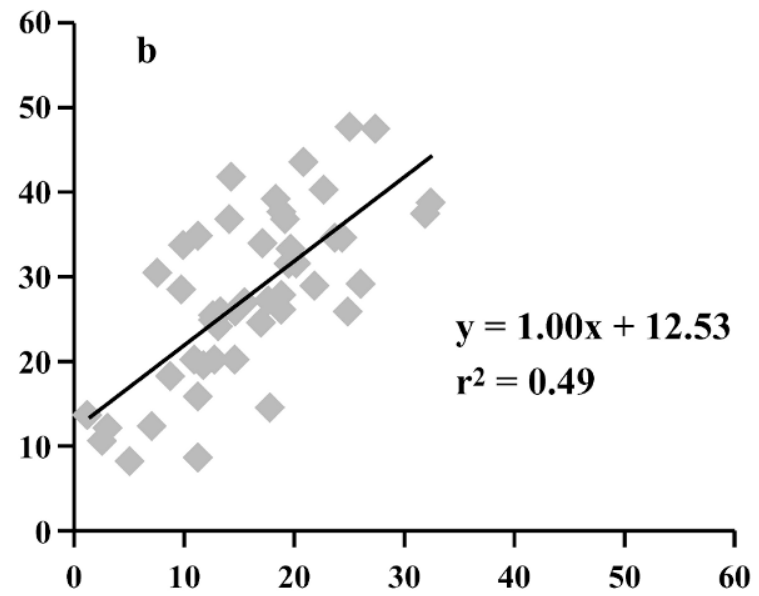

Feeding time (min) after feed delivery when feed was delivered at time of milking

Figure 2. The relationship of feeding time (min) during the 60 min period following a) the return from milking and b) the delivery of fresh feed measured on dairy cows provided with either fresh feed upon return from milking or fresh feed $6 \mathrm{~h}$ after milking. Feeding time was averaged for $7 \mathrm{~d}$ per treatment of 48 cows (4 groups of 12) fed twice a day

the measures of feeding behavior indicated that cows varied in their response to treatment, and this same variation might also have occurred in individual DMI. The effect of treatment on DMI and milk yield could be properly assessed in a future study using equipment that accurately measures individual DMI and longer treatment periods to assess the effect of these treatments on milk yield.

Despite the increase in feeding time when cows were given fresh feed $6 \mathrm{~h}$ after milking, they did not change their total daily lying time. This result indicates that the increase came out of the time cows otherwise spent idle, waiting for feed or for access to the feeding area. It must be noted, however, that cows did change their pattern of lying. The latency to lie down after milking decreased by 20 min when cows were provided fresh feed $6 \mathrm{~h}$ after milking compared with those that had access to fresh feed immediately after milking. Schultz (1985) found that when feed was scarce upon returning from the milking parlor considerably more cows were observed lying down within 15 min compared with when feed was abundant. Unfortunately, Schultz (1985) only reported percentage of cows lying at a specific time after milking and not the latency to lie. Tyler et al. (1997) found that cows that had access to feed after milking stood on average for $48 \mathrm{~min}$ compared with cows that stood for only 21 min when they did not have access to feed. The fact that cows in the current study all had access to feed upon return from milking (even though it might have been delivered $6 \mathrm{~h}$ earlier) may explain why their latency to lie down was greater than that reported by Tyler et al. (1997). Johansson et al. (1999) found that the percentage of cows lying down immediately after milking was affected by the time of feeding. They compared feeding at $1.5 \mathrm{~h}$ prior to milking, at the same time as milking, and $1.5 \mathrm{~h}$ after milking and reported that the delivery of feed at milking caused a lower percentage of cows to lie down within the first hour after milking. In contrast, those cows fed $1.5 \mathrm{~h}$ after milking had the highest percentage lying within the first hour after milking. Unfortunately, comparison of our work with that study is difficult because the cows that were fed $1.5 \mathrm{~h}$ after milking did not have any feed available when they returned from the parlor. As previously mentioned, the cows in our study had feed available for the entire time during the day in which they were in their respective pen. Also, the researchers reported only the percentage of cows lying within a 1$\mathrm{h}$ period and did not measure the latency to lie down.

The practical significance of management practices that affect latency to lie following milking is not fully understood. The common belief is that the longer the animal stands after milking, the lower the risk for bacterial penetration of the teats when the cow eventually lies down. McDonald (1975) measured the dilation of the teat at $0,2,4,6$, and $8 \mathrm{~h}$ after milking and found that the teat was most constricted at $2 \mathrm{~h}$ after milking. Schultze and Bright (1983) injected the teat of lactating dairy cows with a bacterial endotoxin at different time periods after milking and found high penetrability in the first $30 \mathrm{~min}$. This penetrability was much reduced by $2 \mathrm{~h}$ after milking. Unfortunately, as with the study by McDonald (1975), no intermediate samples were taken, so it is difficult to assess the exact time within the first 120 min after milking when the teat is most 


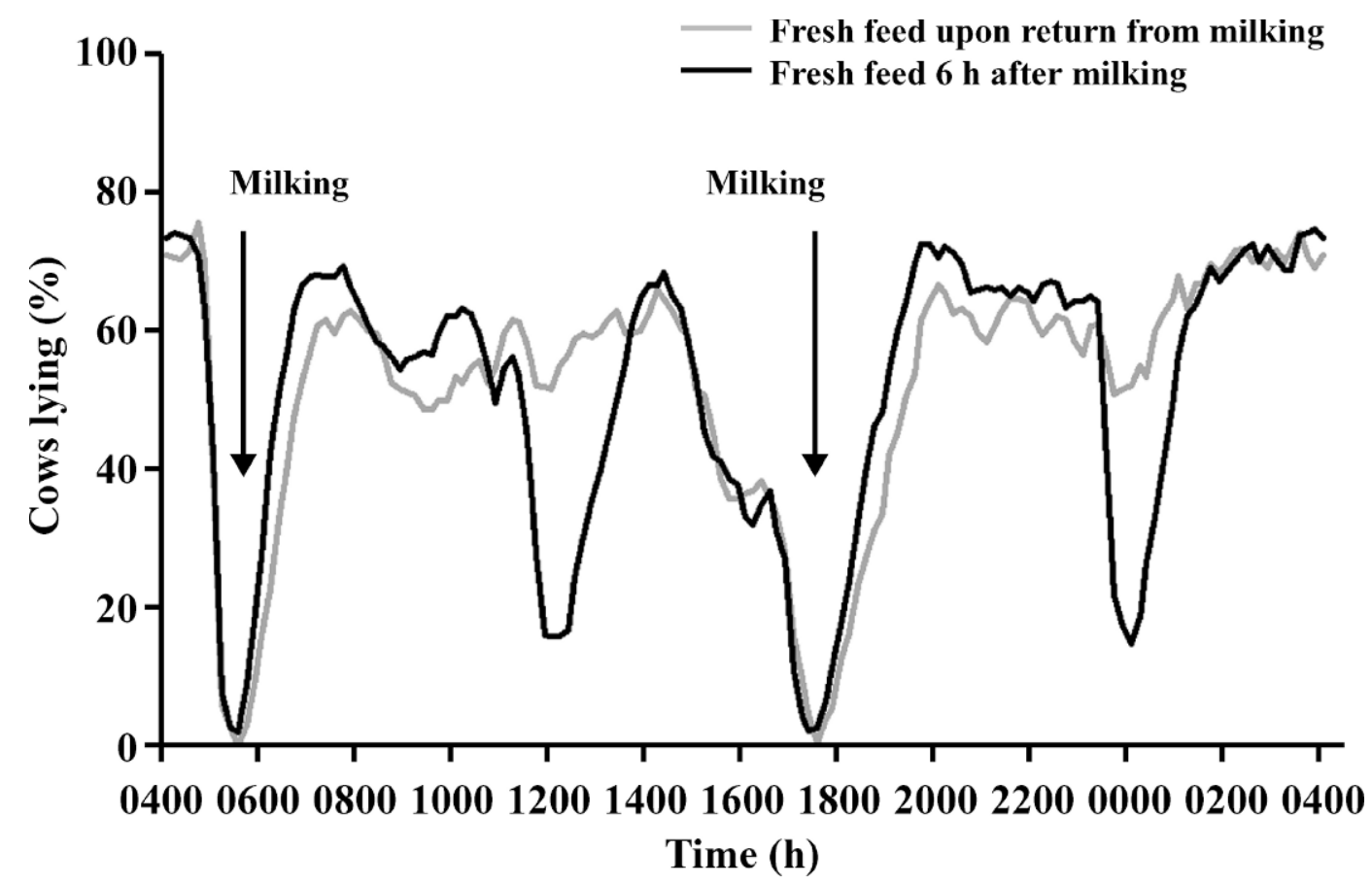

Figure 3. Percentage of cows per group lying over a 24-h period (percentage for each 10-min interval during the day) for 2 treatments: 1) cows were milked and fed at 0530 and $1730 \mathrm{~h}$ and 2) cows were milked at 0530 and $1730 \mathrm{~h}$ and fed at 1130 and $2130 \mathrm{~h}$. Data were averaged for $7 \mathrm{~d}$ per treatment of 4 groups, each containing 12 cows. Data are presented from $0400 \mathrm{~h}$, as this was a time of stable lying activity for both treatments.

constricted and the risk of penetrability by bacteria is lowest. In the present study, because of the restricted length of the treatment periods and the total number of animals, it was impossible to test for any treatment effect on the incidence of mastitis. This effect could be ascertained in a future study designed to test the effect of the length of latency to lie following milking on the incidence of mastitis.

In the present study, there was a tendency for cows to engage in fewer aggressive interactions at the feed alley after the cows returned from milking when they did not have access to fresh feed. Johansson et al. (1999) found that tie-stall-housed dairy cows given no feed 1.5 $\mathrm{h}$ after milking showed fewer social interactions during this period. They attributed this finding to the cows spending more time performing behaviors associated with food searching. In the free-stall environment used in the present study, food-searching behavior by an individual cow will be influenced by social interactions with other cows at the feed alley. In our study, the failure to deliver fresh feed immediately after milking corresponded with a trend for fewer displacements after milking. This trend might have been the result of there being less feed available to fight over at this time and a reduction in the time spent searching for feed. As a result, these cows reduced their time spent at the feed alley at this time, resulting in a decreased latency to lie down compared with those that had fresh feed delivered.

\section{CONCLUSIONS}

Shifting the time of feed delivery away from milking time increased daily feeding time and altered feeding and lying patterns. These results indicate that the delivery of fresh feed has a greater impact on stimulating cows to feed than does the return from milking. The results also indicate that the daily feeding pattern of group-housed dairy cows is largely influenced by the timing of fresh feed delivery.

\section{ACKNOWLEDGMENTS}

We thank the staff and students at The University of British Columbia's Dairy Education and Research Centre and the University's Animal Welfare Program. In particular, we thank Katie Martinolich for her help with running the experiment and with the video analysis. We also thank Agriculture and Agri-Food Canada's Lethbridge Research Centre for the use of their feeding behavior monitoring system. Trevor DeVries was supported by a Natural Sciences and Engineering Research 
Council of Canada (NSERC) Postgraduate Scholarship. The project was funded by the Agriculture and AgriFood Canada/NSERC Research Partnership Support Program made possible by contributions from the Dairy Farmers of Canada.

\section{REFERENCES}

Albright, J. L. 1993. Feeding behavior of dairy cattle. J. Dairy Sci. 76:485-498.

Canadian Council on Animal Care. 1993. Guide to the Care and Use of Experimental Animals. Vol. 1. E. D. Olfert, B. M. Cross, and A. A. McWilliam, ed. CCAC, Ottawa, Canada.

DeVries, T. J., M. A. G. von Keyserlingk, and K. A. Beauchemin. 2003a. Diurnal feeding pattern of lactating dairy cows. J. Dairy Sci. 86:4079-4082.

DeVries, T. J., M. A. G. von Keyserlingk, D. M. Weary, and K. A. Beauchemin. 2003b. Measuring the feeding behavior of lactating dairy cows in early to peak lactation. J. Dairy Sci. 86:3354-3361.

DeVries, T. J., M. A. G. von Keyserlingk, D. M. Weary, and K. A. Beauchemin. 2003c. Validation of a system for monitoring feeding behavior of dairy cows. J. Dairy Sci. 86:3571-3574.

DeVries, T. J., M. A. G. von Keyserlingk, and D. M. Weary. 2004. Effect of feeding space on the inter-cow distance, aggression, and feeding behavior of free-stall housed Holstein dairy cows J. Dairy Sci. 87:1432-1438.

Fregonesi, J. A., C. B. Tucker, D. M. Weary, F. C. Flower, and T. Vittie. 2004. Effect of rubber flooring in front of the feed bunk on the behavior of dairy cattle. J. Dairy Sci. 87:1203-1207.
Hafez, E. S. E., and M. F. Bouissou. 1975. The behaviour of cattle. Pages 203-245 in The Behaviour of Domestic Animals. 3rd ed. E. S. E. Hafez, ed. Bailliere Tindall, London, UK.

Haley, D. B., J. Rushen, and A. M. de Passille. 2000. Behavioral indicators of cow comfort: Activity and resting behaviour of dairy cows housed in two types of housing. Can. J. Anim. Sci. 80:257-263.

Johansson, B., I. Redbo, and K. Svennersten-Sjaunja. 1999. Effect of feeding before, during and after milking on dairy cow behaviour and the hormone coritsol. Anim. Sci. 68:597-604.

McDonald, J. S. 1975. Radiographic method for anatomic study of the teat canal: Changes between milking periods. Am. J. Vet. Res. 36:1241-1242.

National Research Council. 2001. Nutrient Requirements for Dairy Cattle. Natl. Acad. Sci., Washington, DC.

SAS User's Guide. Statistics, Version 5 Edition. 1985. SAS Inst., Inc., Cary, NC.

Schultz, T. A. 1985. Feeding affects post-milking cow activities. California Agric. 39:29-30.

Schultze, W. D., and S. C. Bright. 1983. Changes in penetrability of bovine papillary duct to endotoxin after milking. Am. J. Vet. Res. 44:2373-2375.

Tanida, H., L. V. Swanson, and W. D. Hohenboken. 1984. Effect of artificial photoperiod on eating behavior and other behavioral observations of dairy cows. J. Dairy Sci. 67:585-591.

Tyler, J. W., L. K. Fox, S. M. Parish, J. Swain, D. L. Johnson, H. A. Grasseschi, and R. Gant. 1997. Effect of feed availability on postmilking standing time in dairy cows. J. Dairy Res. 64:617-620.

Wagner-Storch, A. M., and R. W. Palmer. 2003. Feeding behavior, milking behavior, and milk yields of cows milked in a parlor versus an automatic milking system. J. Dairy Sci. 86:1494-1502. 